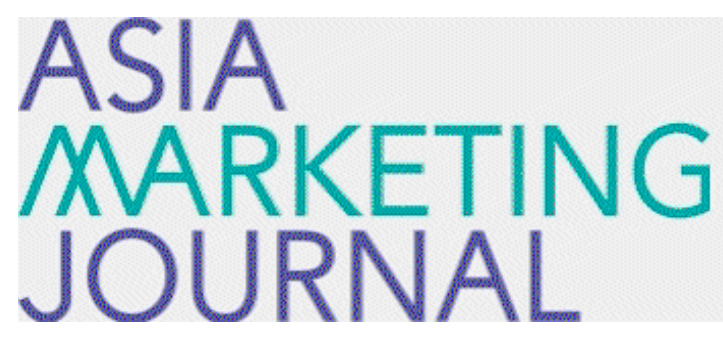

ASIA MARKETING JOURNAL

Volume 15 | Issue 4

Article 8

$1-30-2014$

\title{
Oriental Brewery, Co. Ltd. Vitalizing Cass Brand through Brand Portfolio Strategy
}

\author{
Sung Tai Hong \\ Young Seok Son \\ Woon Bong $\mathrm{Na}$
}

Follow this and additional works at: https://amj.kma.re.kr/journal

Part of the Marketing Commons

\section{Recommended Citation}

Hong, Sung Tai; Son, Young Seok; and Na, Woon Bong (2014) "Oriental Brewery, Co. Ltd. Vitalizing Cass Brand through Brand Portfolio Strategy," Asia Marketing Journal: Vol. 15 : Iss. 4 , Article 8.

Available at: https://doi.org/10.53728/2765-6500.1571

This Article is brought to you for free and open access by Asia Marketing Journal. It has been accepted for inclusion in Asia Marketing Journal by an authorized editor of Asia Marketing Journal. 


\title{
Case Study: Oriental Brewery, Co. Ltd. Vitalizing Cass Brand through Brand Portfolio Strategy
}

\author{
Sung Tai Hong* \\ Young Seok Son** \\ Woon Bong $\mathrm{Na}^{* * * *}$
}

The case study of $\mathrm{OB}$ shows dramatic market dynamics between leader brand vs. follower brand similar to Kirin vs. Asahi in Japan for two decades.

Almost 20yrs ago, the brand status of $\mathrm{OB}$ was dramatically fallen because of the environmental pollution of subsidiary company and harsh competition of rivalry brand. But OB made a ground change in its brand strategy. OB departed from the pride in its past to bet on the new. OB decided to vitalize Cass brand through brand portfolio strategy. They deployed 3 phase articulated marketing plans; Phase I, Acquisition of Cass brand through M\&A and strategic segmentation/targeting (19932005), Phase 2 - Mega Brand Strategy through Line Extension(2006-2009), Phase 3 - Experiential Marketing focused on Young Culture (2010- present).

Finally, OB restored not only brand reputation of Cass and other brands but dominant market position in beer market. Now Cass has been growing rapidly in the last 20 years achieving 50\% M/S.

The three phases shows the typical successful process of brand management and revitalization adopting brand concept management and S-T-P strategy of manufacturing company.

Key words: Beer, line extension, Experiential Marketing, Brand portfolio, Multi-brand strategy

\section{Introduction}

\subsection{The Fall of the Beer Champion}

It would take one event to turn $\mathrm{OB}$ victory on its head. In a space of few years the 70\%$30 \%$ market share balance would completely tip over. In March 1991, an electronics plant in Gumi belonging to Doosan Group caused a quantity of toxic phenolic resin to leak into the Nakdong River, causing a drinking water shut-

\footnotetext{
* Professor, Hanyang University, School of Business(hongst421@daum.net), First author

** Professor, Hallym University, Dept. of Advertising \& P.R. (ysgson@hallym.ac.kr), Corresponding author

**** Professor, Kyeong Hee University, School of Business(wbna@khu.ac.kr)
} 
off in Daegu city and its neighboring areas in Kyeongsang-do. The incident led to a boycott of Doosan Group of which OB was a part. In the beginning, OB seemed resistant, and in the second half of that same year, it seemed to regain its previous market share. However, Chosun beer, aiming to recover from its defeat in the Dry War, launched a well timed attack with a new brand in May 1993. Chosun's new Hite Beer boasted that it was manufactured using 'natural mineral water drawn from a source $150 \mathrm{~m}$ underground' as the key selling point. The tactic clearly meant to take advantage of OB's association with water pollution and the ensuing drinking-water crisis. The strategy worked. Hite's marketing communication strategy centered on water-related slogans such as: "You are careful about water, why not about beer?" or "You can boil dirty water, but can you boil beer?"

Hite's popularity grew, finally dethroning $\mathrm{OB}$ as the market leader, overtaking $\mathrm{OB}$ market share for the first time in November 1996. Capitalizing on Hite's success, Chosun beer changed the company name to Hite Beer (Park, 1995).

Around this time, another threat loomed. A new competition entered the market. Jinro, the leading Korean soju distillery company was a formidable foe with ubiquitous sales channel at its disposal. Partnering up with American beer company Coors, Jinro released Cass beer line in June 1994. This entry turned the game into a three way war, which became a period of trial for Oriental Brewery. In 1995, Oriental Brewery changed the company name to OB Beer, and began to fight back through line extension. $\mathrm{OB}$ introduced new products such as OB Larger, OB Ice, and NEX. However, the strategy was not powerful enough to seriously challenge Hite.

In November 1999, OB acquired Jinro-Coors brewery co., which was ailing from a management crisis. As two companies merged in 2001, the game was reset to duopoly. However the M\&A did not keep the market share from slipping. The combined company's market share continued its fall to $50 \%$ in $1999,47.2 \%$ in year 2000, 43\% in 2003, and finally as low as $39.3 \%$ in 2007. Figure 1 shows the 10 year trend of negative market share growth.

This transitional period in Korean beer market coincided with dramatic changes in OB's management. In 1998, Doosan group went through a management restructuring which involved selling $\mathrm{OB}$ to Interbrew, the Belgian beer group. The Interbrew merged with Ambev, a Brazilian beverage company, forming Inbev, in 2004. Four years later, Inbev merged with Anheuser-Busch, forming Anheuser-Busch-Inbev, a world leader with $50 \%$ of the world market, and 300 brands in its portfolio including such world-leading products as Budweiser, Bud Ice and Beck's. The group resold OB to the private equity fund KKR(Kohlberg Kravis Roberts) in 2009. Despite the confusion caused by 2 ownership changes in less than a decade, OB suc- 
〈Figure 1> OB and Hite Market Share(here)

\section{회사 별 점유율}

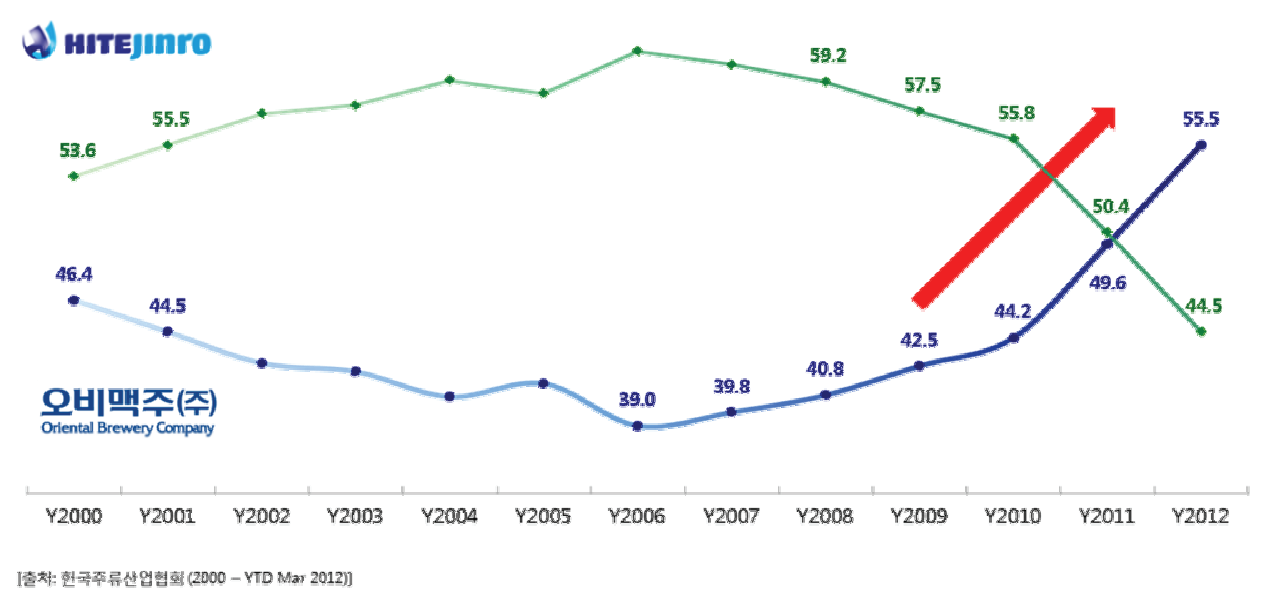

cessfully used the time to re-form its strengths and prepare a heady counterattack against Hite. The period in which $\mathrm{OB}$ was a part of Inbev was especially valuable, as the knowledge acquired therefrom resulted in a dramatic product quality increase. Also, KKR's oversight improved OB's organizational efficiency, equipping the company with structures capable of more proactive marketing. During this period, $\mathrm{OB}$ 'sat on the shoulder of a giant' as it were, gaining insight into global best-practice in the beer industry, preparing to strike back.

This paper is on how OB fell from its absolute market dominance to a secondary position, then how it recovered its top market share through precise, phase-by-phase brand strategy planning and execution. Especially, the research focuses on decision making criteria by which $\mathrm{OB}$ chose the brands on which to con- centrate its resources.

\section{Complete Restructuring of $\mathrm{OB}$ Brand Portfolio Strategy}

Stopping at nothing to regain the market dominance it once commanded, $\mathrm{OB}$ made a ground change in its brand strategy. $\mathrm{OB}$ departed from the pride in its past to bet on the new. Despite multiple brand renewal effort, it seemed clear that customers were not warming up to $\mathrm{OB}$. $\mathrm{OB}$ decided to abandon its investment in $\mathrm{OB}$ brand and decided to concentrate on Cass beer lines. Cass was highly patronized by the loyal consumers, and its growth showed promise.

Fully understanding brand loyalty is one of 
the important factors of brand equity (Aaker, 1991). New Cass marketing strategy can be divided into three phases as can be seen in Figure 2.

OB's executed a three-phase strategy aimed at vitalizing its brand. The first step was deciding that Cass brand which it acquired through M\&A will be the centerpiece of the newly vitalized $\mathrm{OB}$ brand. $\mathrm{OB}$ expanded and restored its sales network with this new strategy in mind. At the same time, OB concentrated a large portion of its resources to new products R\&D.

The second phase was introducing the new products resulting from phase-one $R \& D$ to the market to round out the Cass brand line-up. The second phase marketing and communica- tion would revolve around the new product launches.

The third phase consists experiential marketing plans, aimed at integrating CASS into target customer's day to day life, which would result in renewed vitality to the entire $\mathrm{OB}$ brand image. This is made possible by variety of options available due to a complete CASS line-up introduced during the first two phases.

In order words, in the first phase, the resources gained during M\&A was prepped for active and organized deployment; in the sec- $^{-}$ ond phase, a complete line-up around CASS, the new champion, was built in order to give customers wider range of choice; and finally in the third phase, brand was combined with culture by deploying a strong experiential market-

〈Figure 2〉 Cass Brand Vitalization in 3 phrases

Source of M/S: Korea Alcohol Liquor Industry Association

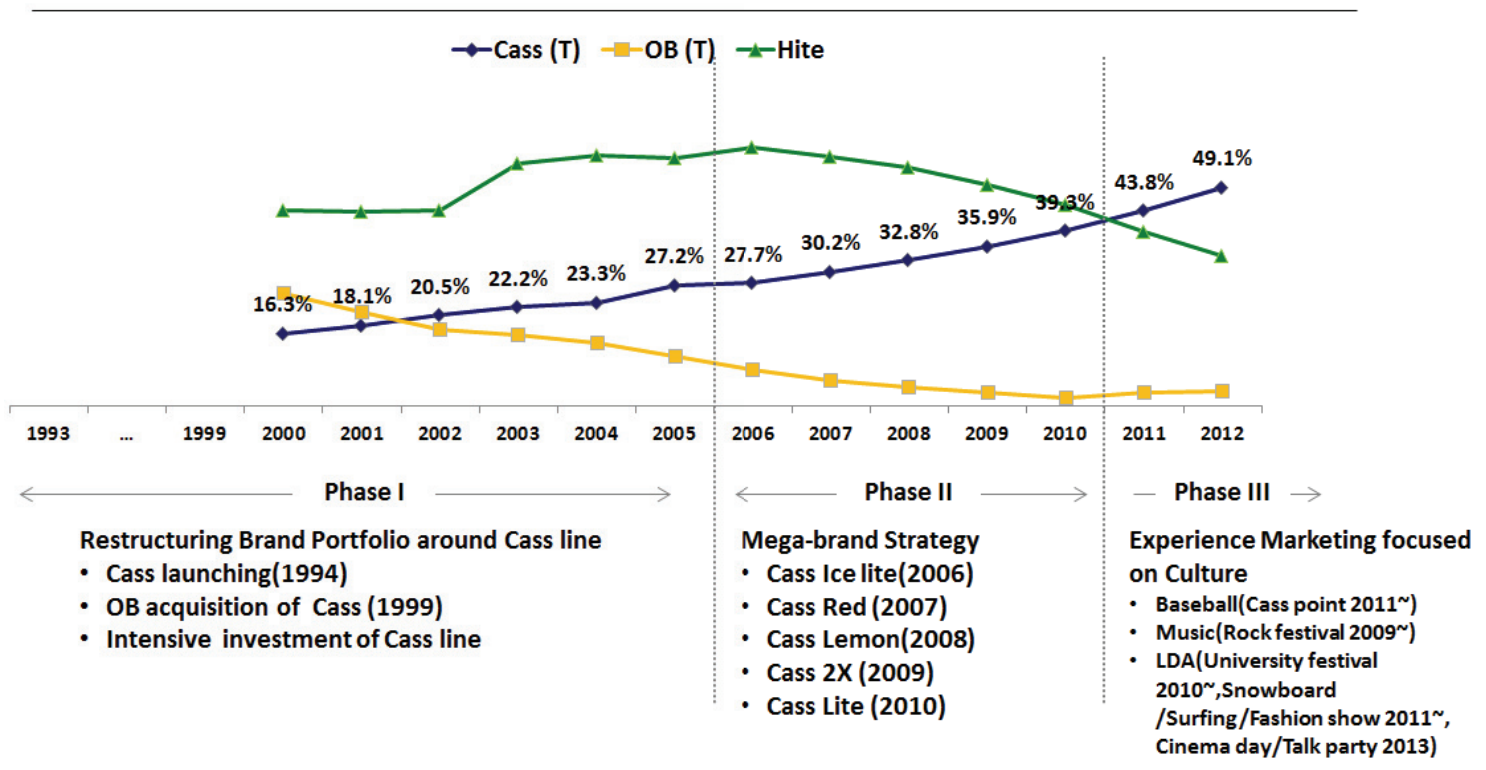


ing scheme. The overall plan corresponds to the introduction-elaboration-fortification steps laid out by the Brand Concept Management theory (Park, Jaworski \& MacInnis, 1986.)

\subsection{Phase I, Acquisition of Cass brand through M\&A and strategic segmentation/targeting (1993-2005)}

\subsubsection{In 1999, OB acquired Cass through an M\&A deal}

Afterward $\mathrm{OB}$ bet on Cass to champion its attack on Hite's market dominance. Cass was manufactured using a new manufacturing technique called the 'Fresh' method. The 'Fresh' engineering method adopted NASA's Micro Ceramic Filter technology to eliminate heating from the brewing process. The resulting beer is more crisp and tangy, attributes preferred by younger drinkers and serious beer lovers. OB's strategy was to use Cass to conquer the 'good drinkability' market segment, the largest identified beer market segment in Korea, by capitalizing on Cass' "punchy, high-carbonate" taste. The product's advantageous physical characteristic was at the center of the new marketing slogan : "Tok! Cass!" Through this campaign, Cass could own the 'refreshing' attribute, identified as the most important $\mathrm{KBF}$ (key buying factor) for Korean beer consumers. Cass focused its growth strategy on LDA (legal-drinking-age, in other words, young drinkers in early their 20s) segment, differentiating itself from competition, who targeted the larger drinking population in 30s 40s age group.

The LDA segment, being new to the market, tend to have lower established brand loyalty, and therefore is more responsive to marketing. However, this is also the formative years for the young beer consumer where he develops his tastes and settles on a brand. This means that the lifetime value of a LDA consumer is higher than older age groups. Another advantage of LDA targeted marketing strategy was that their ignition effects on secondary target consumers. The consumers between 30s and 50s age range tend to imitate the consumption habits of the young. The importance of the consumer in their 20s has been increasing because the spillover term of trend transition has quickened from 3 year to 1year.

The consistent communication message focused on the "refreshing and exciting" benefits played a major role in the rise of Cass as OB's new prize horse. Also the factors are one of the main dimension of brand personality (Aaker, 1997).

\subsection{Phase 2 - Mega Brand Strategy through Line Extension(2006-2009)}

In order to accelerate the market growth of Cass, OB decided to line up the Cass, turning into a line extension. As Nijssen(1999) noted, among the range of strategies available to a 
company, line extensions are an important way to keep a brand alive and to realize incremental financial growth. The line extension is pertinent strategy to expand market share (Lomax \& McWilliam, 2001). According to that study, all the line extensions in this study were bought by consumers with a greater propensity to purchase the parent than the average category purchaser.

\section{〈Figure 3〉 Buzz \& WOM (Word of Mouth)} Index (Hite vs. Cass)

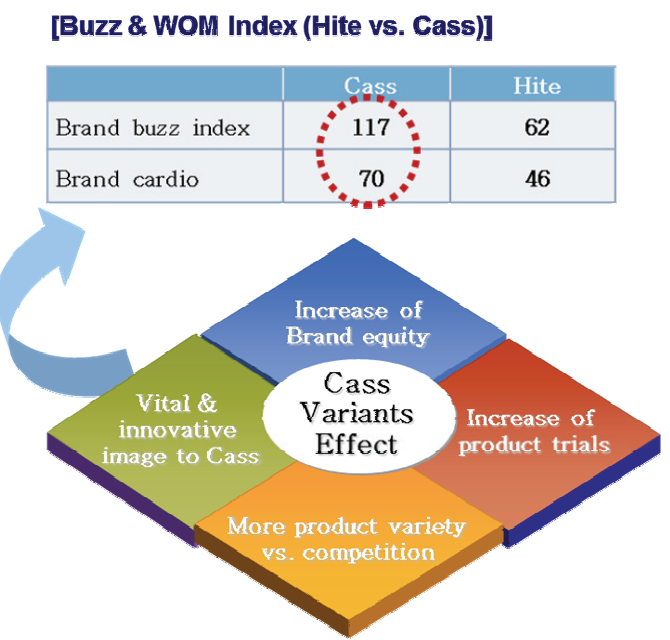

(Source : Nielsen Brand Reports, May, 2009)

The mega-brand strategy through line extension had two major purposes. The first purpose was to satisfy the diversified consumer needs and trend groups in order to attract brand preference and to increase sales for the entire Cass brand family. The second purpose was to counter the competitors' flood of SKU in the stores by introducing variants, Cass could oc- cupy more shelf space and thereby increase the probability of choosing from consumers.

Whenever OB launched each extended product, they engendered the buzz effect, instrumental in increasing Cass's consumer word-of-mouth, and promoting its image as an innovator (Figure 3). Until 2005, Cass "Fresh" was the sole Cass runner. However, beginning year 2006, Cass line rapidly started to expand as shown on Figure 4.

In 2006, It was revealed based on a market research that consumers drink less beer because of the feeling of pigging out whenever they drink beer. Countering this phenomenon, $\mathrm{OB}$ launched less filling Cass Ice Light. This low_calorie line was manufactured using the Dry Mill Method, in which barley husks are removed before being brewed, then fermented at freezing point, removing impurities. Thus produced beer is less sour and cleaner tasting.

The consumer research also showed that the customers were not content with beer's low alcohol content. The complaint was that, with beer, the intoxication takes place too slowly. The need gap created a behavior where consumers would blend beer and soju into a drink known as "The Soju Bomb." In response, OB introduced a high 6.9\% alcohol content beer dubbed Cass Red in 2007. OB utilized high fermentation process for this beer resulting in both higher alcohol content and stronger flavors. For this beer, $\mathrm{OB}$ chose high quality aromatic hop and crystal malt. This was an upmarket 


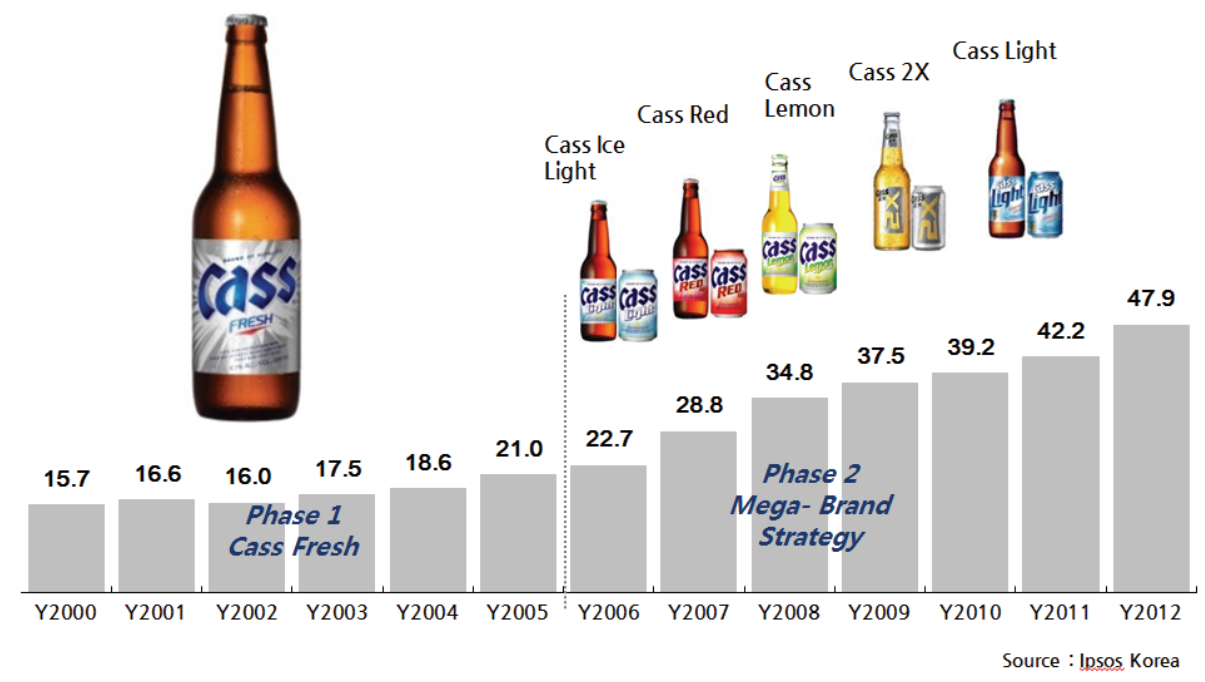

move, as Cass Red costs 20\% more to manufacture than the previous product.

In 2008, OB also expanded down market with Cass Lemon, a natural lemon juice flavored beer for women. Cass Lemon aimed to deliver a fresher taste by adding acid lemon flavor to the tangy Cass. One year later, Cass 2X was introduced as a new member, a low alcohol, high carbonate variety aimed at young people with active lifestyle.

Overall, Multi brand strategy of Cass was a half-success. The strategy did generate the desired buzz effect for Cass brand family, and did increase the demand for the original brand, Cass Fresh. However the sales of variant lines usually went into a nosedive a year after their launch, and none grew into major brand of its own. OB did not back up variant brands with meaningful, additional investments after the first year. Some variants acquired a loyal following but stopped at becoming niche market brands, ultimately failing at bringing in significant sales.

In 2010, OB restructured its Cass Brand Portfolio. Cass Ice Light was identified having the potential among the variant brands and was relaunched as Cass Light. As a result, Cass Light have shown a significant quantitative growth. But the market laggard brand of Cass 2X was removed. The current Cass brand architecture is composed of four brands: Cass Fresh, Cass Light, Cass Red and Cass Lemon.

\subsection{Phase 3 - Experiential Marketing focused on Young Culture (2010- present)}

By 2011, OB was becoming weary of growth 
through line extension. $\mathrm{OB}$ decided to reengineer its entire brand architecture and product strategy. As a result of that review a new brand platform was reorganized, as can be seen on Figure 5

Cass defines its brand essence as 'excitement.' $\mathrm{OB}$, recognizing that it lacks a brand icon strong enough to support its brand pyramid, chose music and baseball as its icons. These activities are a good fit of $\mathrm{OB}$ brand essence. At the same, they possess a strong appeal for LDA market. The brand icons let the customers experience firsthand the brand essence, They build sensory, emotional, cognitive, active, emotional and value based relationship between the customer and the brand (Schmitt, 1999). OB decided to apply this theory to Cass marketing. $\mathrm{OB}$ had rich previous history in using baseball to boost its brand. In the 1980s, OB Bears, a Korean professional league baseball team was an iconic figure in Korean baseball. However, the team had since fallen into oblivion. Hite, the competition was also selling beer on baseball stands. However the consumers did not associate Hite with baseball. In order to turn its professional baseball brand into a resource, OB needed a breakthrough solution. It was difficult to mobilize mass media due to legal restrictions. Korean advertising laws allowed beer commercials to air only after 10 PM.

OB teamed up with Korean Baseball Organization

〈Figure 5〉 Brand Platform

\section{Cass Brand Strategy - Cass Brand Pyramid}

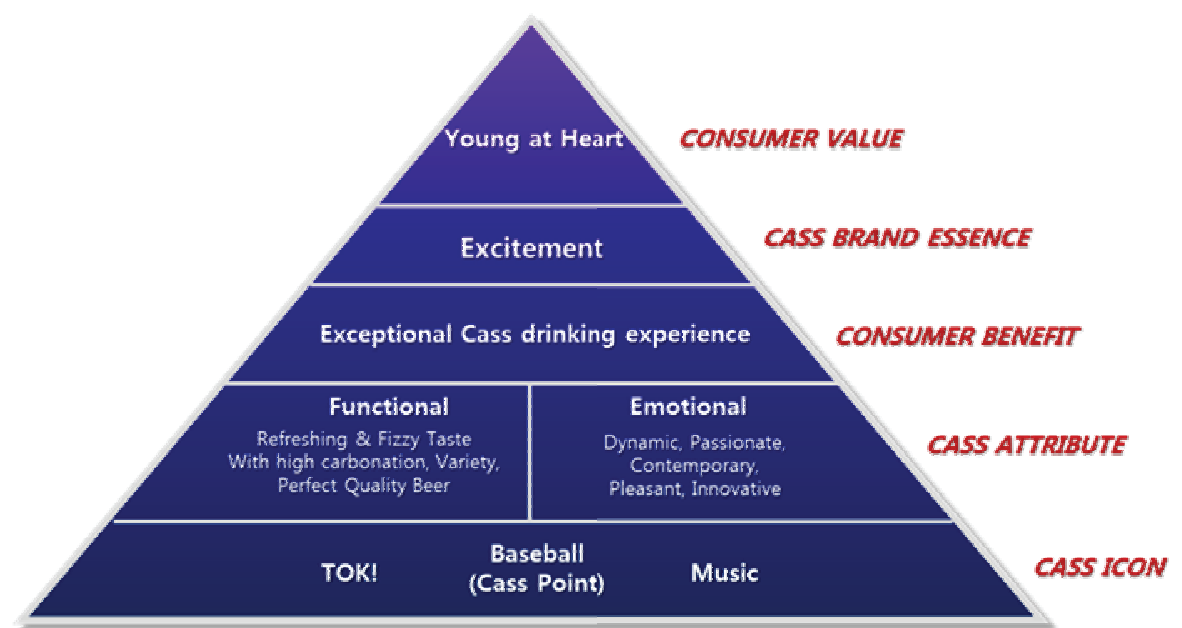

\section{카스 고유의 특별한 경험을 통해 짜릿한 즐거움을 제공함으로써 소비자들의 마음 속에 젊음을 느끼게 해주는 맥주}


and MBC Plus sports network to introduce an innovative baseball player ranking system called the Cass Point System. Cass Point System allowed Cass to gain mass media exposure through baseball before 10 PM. Cass Point System's overall media value to Cass is estimated at 25bn KRW. Year end event, Cass Point Award Show is now Korea's biggest baseball award show. Cass is now clearly Korea's official professional baseball bear.

$\mathrm{OB}$ also introduced an online and mobile fantasy baseball game based on Cass Point System called Cass Point Line-up, where potential customers can actively interact with Cass Point System. As a result of these efforts, now 70\% of beer customers recognize Cass Point, and $60 \%$ of the respondents said that Cass Point made them more likely to purchase Cass beer.

Cass pursued and obtained joint-promotion exclusive sales agreements with 5 major professional baseball teams. Cass is now sold at major games. Cass also hosts a baseball league for the average man called "Cass Final."

Cass offers its beer in variety of baseball themed packaging such as Cass Point special cans and packages. This allows the customer to form visual and tactical association with Cass and Cass Point.

OB's also concentrated it cultural marketing effort into an arena particularly dear to 20 something consumers: Music. OB organized Cass concerts at college festivals across the country, offering electrifying Cass brand experience. Cass sponsors rock concerts, as well as guerilla street concerts targeting specific business districts. A more participatory experience can be had through on-campus audition show 'Cass Got Talent.' Cass' cultural marketing philosophy is that Cass should be in every place that the young gather, Cass organizes monthly club parties and and cinema days. The idea is that young people should 'live with' Cass brand all year long. Culture and lifestyle marketing specifically aimed at the young made the brand extremely relevant to consumers in their 20s and 30s.

〈Figure 6〉 Print Advertisement of Cass Light

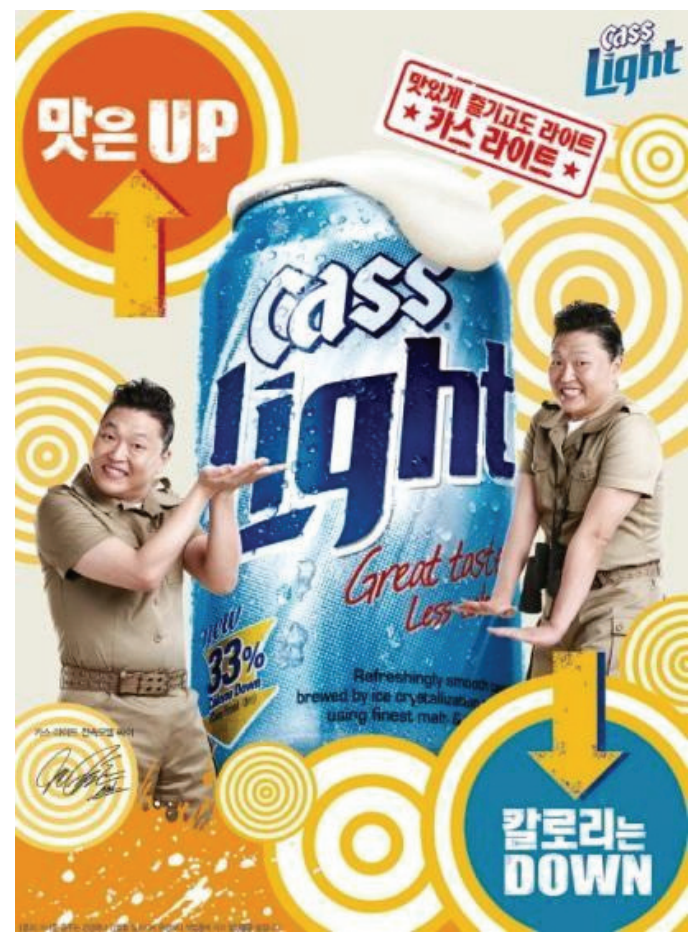

Cass' cultural marketing could be described as 'branded entertainment,' where technics of 
〈Figure 7〉 Cass Cultural Marketing Efforts
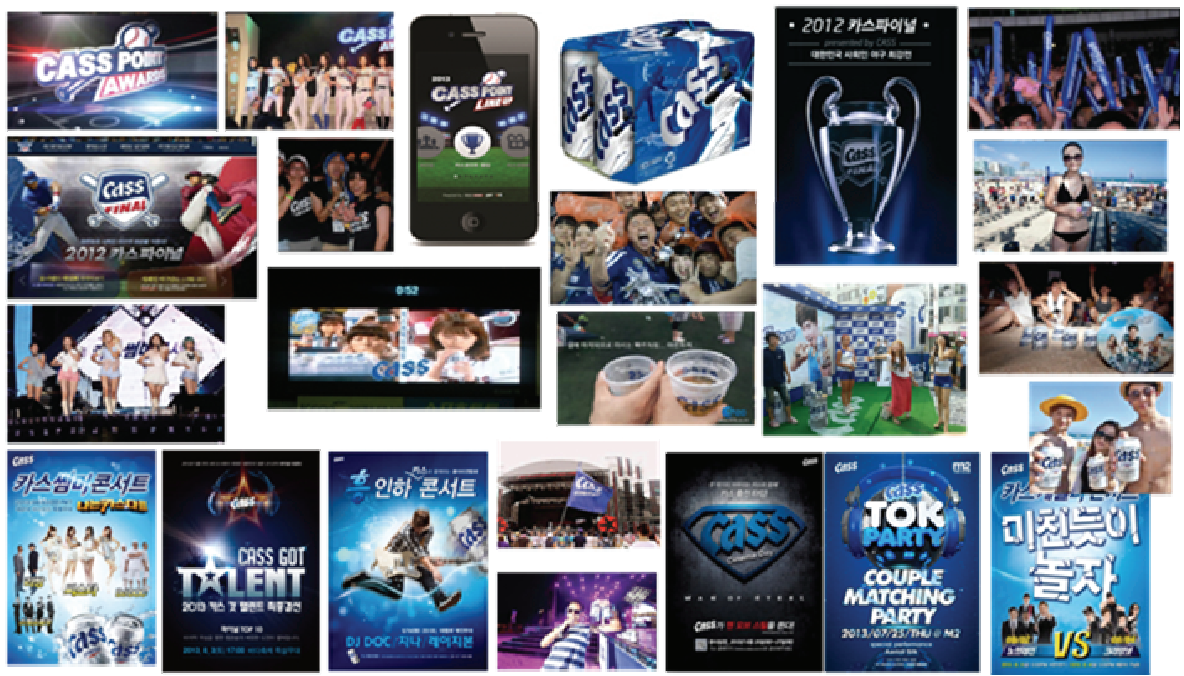

entertainment industry are combined with marketing tools into a more friendly and interesting communication medium. All forms of entertainment, regardless of form or genre can become a marketing tool. Movies, TV shows, sports, video games, music and publishing all have something to contribute in communicating a more positive brand image and fusing the brand and its products into a story.

Branded Entertainment is not only centered on the marketing message, but interesting and stimulating contents or stories. The public is more likely to accept messages that approach them as fun and natural rather than obviously commercial. As there are infinite types of entertainment, there can be infinite variety of entertainment marketing. Only question is finding the right combination. Branded Entertainment is a win-win strategy where the marketing success is directly proportional to the emotional satisfaction delivered to the consumer.

$\mathrm{OB}$ also strengthened the functional attribute of the product. The taste is now fresher and packs more punch than ever. In order to deliver fresher products to the consumer, the $\mathrm{ex}^{-}$ piration date has been shortened and new patented air-tight 'Fresh Cap' was introduced. The Fresh Cap was designed to make a distinct 'Tok' sound as an audible sign of the product's freshness.

\section{Conclusion}

\subsection{Cass up to today}

Above 3 phases of Cass marketing was 20 
years in the making. The Cass is now no. 1 beer in Korea. Thanks to Cass, OB was able to overtake Hite for the first time in 17 years, and return to the No. 1 position in the Korean beer market. Its success measured can be measured by various indexes as in Figure 6 and Figure 7. Cass' rapid growth turned the table on the entire beer market. Now Cass is the preferred brand of 1 out of every 2 beer drinkers in Korea. These revolutionary results have established Cass as 'the' Korean beer brand.

$\mathrm{OB}$ achieved notable results on cost front as well. OB was able to check the cost increases that inevitably accompany a rapid market share growth. Despite Cass' rapid market share increase, OB's marketing cost as a percentage of sales is still below that of Hite, the results of smart management decision that decided to concentrate on branding.
The success factors of Cass are originated from innumerable factors. However, few of the most important factors can be summed up as follows.

Firstly, Cass had a very clear SegmentationTargeting-Positioning strategy. It is the most important way of marketing strategy(Kotler \& Armstrong, 2009). Cass dominated the largest Korean beer drinking segment, namely those with a preference for 'good drinkability', by capitalizing on Cass' 'freshness' attribute. Also clear LDA focused targeting allowed it to develop a unified image as "the young beer", providing excitement and stimulation.

Secondly, Cass focused its energy on experiential / cultural marketing that contacted consumers at close quarters. Learning its target customer's lifestyle and movements, Cass could be everywhere in which target customer was

〈Figure 8>Brand Preference Trend of Cass

\section{Cass Winning Strategy:}

Cass brand preference has enjoyed sustained growth and secured the top of consumer brand preference

Cass (T) vs. Hite, Annual brand preference Trend

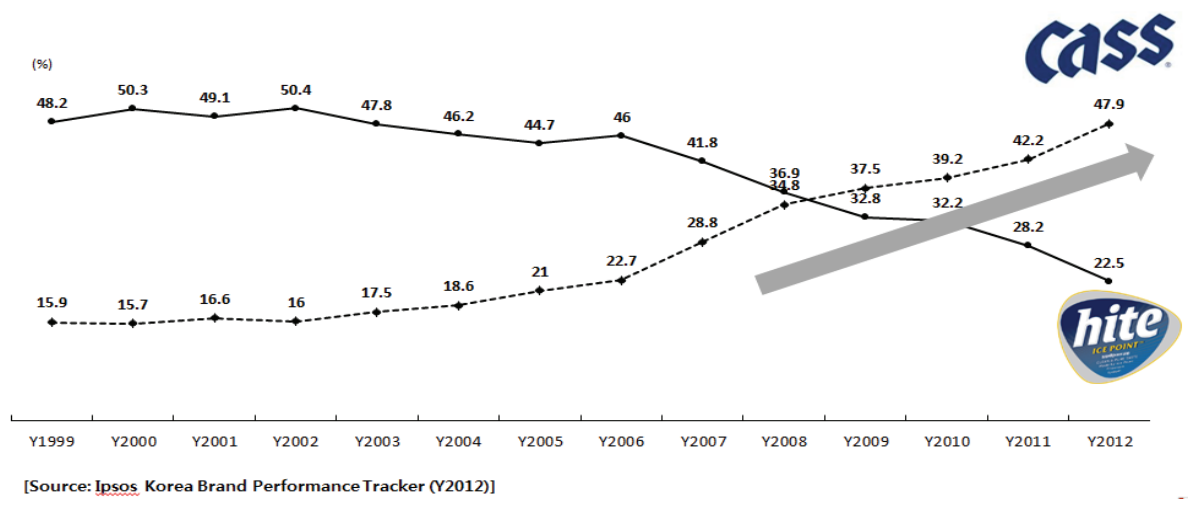


having fun. By using a 360 degree approach with presence on college campus, baseball stadiums, dance clubs, festivals, and movie theatres, the brand received credit for offering joy and laughter.

Thirdly, Cass' relentless innovation became an endless source of buzz. Its technical innovations led to the best tasting domestic beer. Strategic line extensions generated not only generated word-of-mouth but also satisfied a varied range of consumer needs. Logistics innovation allowed Cass to reduce its inventory, reduce the time between manufacturing and consumption.

Also these logistical advantages when combined with product innovations such as the air-tight "fresh cap", meant altogether that fresher beer was delivered to the end user. This means, they fully adopted the sonic branding methodology (Fulberg, 2003).

Fourthly, Cass achieved a point-blank, business district by business district marketing system by collaborating closely with its sales network. The entire supply value chain from wholesale to retail to point-of-sales was operated through a coordinated, strategic collaboration between the marketing department and the sales organizations. This allowed $\mathrm{OB}$ to gain market supremacy in young and trendy neighborhoods of Gangnam and Hongdae, and to take away the young beer drinkers from the southern provinces, where Hite was maintaining its dominance, undermining Hite's baseline.
Fifthly, Cass marketing team was composed of a small elite 'dream-team' both within and outside the company organization. A small team of around 20 people manage brands with combined annual sales of 2 trillion KRW. This team constantly develops ideas for forming larger relational marketing network through strategic partnerships. In the beginning of each December, Cass hosts the Marketing Partnership Conference. 20 partnership companies are invited to share the company's past accomplishments and future visions. The conference is also a congratulatory occasion, through which $\mathrm{OB}$ fosters a family-like, loyalty based relationship with its partners. $\mathrm{OB}$ partners have become proactive innovators with strong sense of ownership in $\mathrm{OB}$ products. The partners are probably the single most important factor in OB's success.

Since 2010, Cass is also positioning itself as an environmentally friendly company, respectful of nature. Its Fresh Cass, Fresh Earth slogan aims to instill a 'green spirit' in four axial areas: the product, the company, the customers, the community. Cass introduced 100\% recyclable packaging, as part of a concerted effort to reduce CO2 emissions. All Cass packagings are as of now green certified, and people are urged to recycle through a Green TVC campaign that began in 2012. "Green Saving Project" was also launched at its manufacturing plants. OB replaced its manufacturing equipment to environmentally friendly versions, and improved its manufacturing system and ach- 
ieved reduction in both energy use and $\mathrm{CO} 2$ emission.

Green Marketing based on OB's Corporate wide CSR (Corporate Social Responsibility) efforts includes international operations. For a few years, OB has been operating 'Foster Forest of Hope' campaign in Mongolia. Through these efforts OB has been able to obtain government recognition, receiving Korea's most prestigious environmental award ; "Korean Green Management Grand Prix" awarded by the Office of Prime Minister.

\subsection{Future Challenges}

Cass has been growing rapidly in the last 20 years achieving 50\% M/S. However, holding onto $50 \%$ market share in any single industry is a great challenge for any company. Most of all, the dominant market is going to fragmented (Al Ries \& Trout, 1994). Over 200 imported beer brands are aggressively targeting young beer drinkers in their 20s, Cass's traditional customer base (Korea Microbrewery Association, 2012). Hite's new Hite D line has been jumping on the bandwagon, imitating and deliberately going after Cass target consumers. Also there is a strong prejudice among beer drinkers that Korean beer, which is mainly of the larger variety does not taste as good as imported ales. How Cass will maintain its leadership position and grow despite all these threats is a major homework for everyone involved in Cass marketing.

\section{References}

Aaker,. A.(1991), Managing Brand Equity, Free Press; New York.

Aaker, J.(1997), "Dimensions of Brand Personality," Journal of Marketing Research, 34(Aug),347-356.

Al Ries and Jack Trout (1994), The 22 Immutable Laws of Marketing: Violate Them at Your Own Risk!, Harper Business; New York.

Doosan Group (1996), From Baeogae to the World; 100 Years of Doosan Group, Dept. Planning \& Coordination ; Seoul.

Fulberg, Paul (2003),"Using Sonic Branding in the Retail Environment," Journal of Consumer Behaviour, 3(December), 193-198.

Korea MicrobreweryAssociation (2012), News. Retrieved From the Korea Microbrewery Association website: http://www.microbrewery. or.kr/frame5-2cont.htm? mode $=5 \&$ aq_id $=208$.

Kotler, P. \& G. Armstrong (2009), Principle of Marketing, $13^{\text {th }}$ Edition, Prentice Hall; New York.

Lomax, W. \&, G. McWilliam (2001), "Consumer Response to Line Extensions: Trial and Cannibalisation Effects," Journal of Marketing Management, 17(3/4), 391-406.

Nijssen, Edwin J. (1999), ”Success Factors of Line Extensions of Fast-Moving Consumer Goods", European Journal of Marketing, 
33(5/6), 450-474.

Park, Bok Dong(1995), The Changing Fate through Hite, Myeong Sung Publishing; Seoul.

Park, C.W., Jaworski, B.J. and MacInnis, D.J. (1986), "Strategic brand concept-image management," Journal of Marketing, 50 (October), 135-45.

Schmitt, Bernd H.(1999), Experiential Marketing. How to Get Customers to Sense, Feel, Think, Act and Relate to Your Company and Brands, The Free Press; New York. 